\title{
Evaluation of Increase in the Adhesion Molecules (Icam-1, Vcam-1) according to the Types of Atrial Fibrillation
}

\author{
Kilci $H^{*}$, Koksal C, Lutfu B, Ilksen AG and Orhan $O$
}

Sisli Etfal Education and Research Hospital, Istanbul, Turkey

\begin{abstract}
Aim: we aimed to evaluate the levels of vascular cell adhesion molecule-1 (vcam-1) and intercellular adhesion molecule-1 (icam-1) at the patients with valvular and nonvalvular atrial fibrillation.

Methods: 45 control patient with normal sinus rhythm and 44 patients with valvular atrial fibrillation (vaf) or nonvalvular atrial fibrillation (nvaf), total 89 subjects whose Coronary arteries were found to be normal with angiography were included in the study.

Results: there was not any significant difference between the control and atrial Fibrillation (af) group in term of plasma icam- 1 levels $(706 \pm 180 \mathrm{mg} / \mathrm{dl}$ vs. $671 \pm 132 \mathrm{Mg} / \mathrm{dl}, \mathrm{p}=0.313)$. Plasma vcam- 1 levels were found to be higher in the af group than The control group $(1169 \pm 246 \mathrm{mg} / \mathrm{dl}$ vs. $1072 \pm 229 \mathrm{mg} / \mathrm{dl}, \mathrm{p}=0.056)$. In the atrial Fibrillation group there were 17 vaf and 27 nvaf patients. In the subgroup analysis According to the type of atrial fibrillation; there were statistically significant differences between the control and vaf and nvaf groups in terms of vcam- 1 levels (1260 \pm 291 vs. $1113 \pm 198$ vs. $1072 \pm 229, p=0.021$ ). It is shown that the detected differences in Term of vcam- 1 between the atrial fibrillation group and control group are particularly Due to the differences between the vaf and control groups (vaf and control groups; $1260 \pm 291 \mathrm{mg} / \mathrm{dl}$ vs. $1072 \pm 229 \mathrm{mg} / \mathrm{dl}, \mathrm{p}=0.016$, respectively). For icam- 1 levels any differences between vaf and nvaf groups were not detected (748 \pm 203 vs. $680 \pm 163$ vs. $671 \pm 132, p=0.216)$.
\end{abstract}

Conclusion: in this study, vcam-1 levels were found to be higher at the patients with vaf. We think that increased vcam-1 levels at the patients with vaf can be related with the increased risk of thromboembolic events.

\section{Keywords: Atrial fibrillation; Vcam-1; Icam-1}

\section{Introduction}

Atrial fibrillation (af) is the most frequent arrhythmia in the adult ages and related with the one third of the hospitalizations for rhythm disorders [1]. Morbidity and mortality of the patients with atrial fibrillation increase significantly according to the patients without af [2]. Stroke is the most important cause of morbidity at these patients. Non-valvular af (nvaf) increases the risk of stroke 5-folds and valvular af (vaf) increases the risk 17-folds [3-5]. In order to decrease the morbidity and mortality due to the atrial fibrillation, medical and electrical treatments are heavily used [6-8].

Hemodynamic changes seen in the structural heart diseases, neurohumoral activation, cellular interactions and other factors cause atrial tension and interstitial fibrosis [9]. These changes affect the electrical and structural features of the atrial tissue that plays an important role in the development of af.

As a result of atrial fibrillation, endothelial impairment and prothrombic endothelial changes develop at atriums [10]. Many structural changes that are defined in the atrial tissue of patients with atrial fibrillation are related with the changes which develop in the signal transducing pathways at the cell level [11] like st2/1l-33 (suppression of tumorigenicity 2/interleukin 33) pathway's role on myocardium remodeling [12].

A group of cellular surface molecule that maintains the adhesive interactions between the endothelial cells and leucocytes are defined. It is shown that these molecules that are called adhesion molecules are involved in the regulation of events such as histogenesis, embryogenesis, cell growth, cell differentiation and inflammation [13]. Some adhesion molecules that increase in the blood stream can contribute to intravascular thrombus development by increasing the cell collection and adhesion [11]. Intercellular adhesion molecule-1 (icam-1) which is an adhesion molecule from the immunoglobulin super family is expressed particularly from endothelial cells, lymphocytes, smooth muscle cells, monocytes and macrophages [14]. Another adhesion molecule in this group is called vascular cell adhesion molecule-1 (vcam-1) and it is expressed especially depending on endothelial cells, antigen presenting cells, stromal cells of bone marrow, embryonic tissue and synovial tissue [15]. Endocardial adhesion molecules (icam-1 and vcam-1) can play a role in inflammation and prothrombic mechanisms or relationship between these two roles. In many studies, vcam-1 and icam-1 have been claimed to be responsible for the atrial thrombus, valvular and myocardial damage [10,16-20].

In patients with valvular atrial fibrillation (vaf), the risk of developing of atrial thrombus and thromboembolic event is much higher than in the subjects with nvaf. We consider that this situation can be related with the adhesion molecules. In this study, we aimed to compare the levels of icam-1 and vcam-1 in patients with vaf, nvaf and normal sinus rhythm.

*Corresponding author: Kilci H, Sisli Etfal Education and Research Hospital, Istanbul, Turkey, Tel: 0905336447318; E-mail: mail@expertscape.com

Received November 11, 2015; Accepted November 26, 2015; Published December 12, 2015

Citation: Kilci H, Koksal C, Lutfu B, Ilksen AG, Orhan O (2015) Evaluation of Increase in the Adhesion Molecules (Icam-1, Vcam-1) according to the Types of Atrial Fibrillation. J Vasc Med Surg 3: 234. doi:10.4172/2329-6925.1000234

Copyright: ( 2015 Kilci H, et al. This is an open-access article distributed unde the terms of the Creative Commons Attribution License, which permits unrestricted use, distribution, and reproduction in any medium, provided the original author and source are credited. 


\section{Materials and Methods}

\section{Patient group}

We used 45 subjects with normal sinus rhythm as the control group and 44 af patients whose coronary arteries were found to be normal between January 2008 and May 2009 as the experiment group. 27 of this group were with nvaf and 17 of them were with vaf.

Demographic features, major cardiovascular risk factors (hypertension, hyperlipidemia and diabetes) and laboratory findings were all recorded.

As a result of the echocardiographic tests, patients with stenosis or failure symptoms due to the rheumatic valvular disease or atrial fibrillation and patients who were administered surgical valvular replacement/repair due to these causes were defined as vaf. The remaining cases of atrial fibrillation outside of them were considered as nvaf. In order to detect the svcam-1 and sicam-1 levels, venous blood samples were obtained and all samples, at the same time, were stored at -80 C. Serum vcam-1 and icam-1 levels were measured by using the elisa technique with ray bio human sicam-1 elisa kit for icam and ray bio human svcam-1 elisa kit for vcam.

After all patients had been informed about the study, approval forms were signed and taken together with the approval of the ethical committee.

\section{Statistical Analysis}

Continuous variables were defined as mean \pm standard deviation and quantitative variables were defined as number and percentage. Appropriateness of the variables for normal distribution was evaluated with "shapiro-wilk" test. At binary comparisons, appropriateness of continuous variables for normal distribution was compared with " $t$ test" and "mann-whitney u test". Continuous variables in the multiple groups ( $>2$ ) were compared with one way variance analysis (anova). Values which were statistically and significantly different between the groups in the one way variance analysis were compared with multiple comparison methods such as multiple comparison procedures and tukey hsd (tukey's honestly significant difference test). Qualitative variables in all of the groups (gender, diabetes, hypertension, smoking etc.) were compared with chi-square test. For all of the statistical analyses, "spss for windows version 12" software was used. Calculated $p$ value $<0.05$ was accepted as statistically significant.

\section{Results}

Total 89 patients of which 44 with af and 45 with normal sinus rhythm at the electrocardiography as control patients who do not have coronary artery disease were included in the study. Demographic features of the groups were shown in Table 1. While both groups were similiar in terms of gender (male in the control group $n=16$ (35.6\%), male in the atrial fibrillation group=15 (\%34.1), $\mathrm{p}=0.19)$, there was a statistically significant difference in terms of the average ages ( $51 \pm 8$ vs. $62 \pm 10, \mathrm{p}<0.001)$ between af and the control group though the average ages were similar in vaf and the control group. There wasn't any statistically significant difference between the groups in terms of diabetes, hypertension, hyperlipidemia, and family history. Biochemical parameters bun, creatinine, total cholesterol and ldl levels were higher in the af group, while hdl and triglyceride levels were higher in the control group. Any statistically significant difference between the groups was not detected in terms of crp levels (Table 1). When the control group and vaf group were compared, any statistically significant difference wasn't detected in terms of age, bun, total cholesterol and ldl levels ( $p>0.5$ ) (Table 2). Vcam-1 and icam-1 distribution within the atrial fibrillation and control groups are shown at Figure 1. There wasn't any difference detected in scope of icam-1

\begin{tabular}{|c|c|c|c|c|}
\hline & $\begin{array}{l}\text { Control } \\
(\mathrm{N}=45)\end{array}$ & $\begin{array}{l}\text { NVAF } \\
(\mathrm{N}=27)\end{array}$ & $\begin{array}{l}\text { VAF } \\
(\mathrm{N}=17)\end{array}$ & $\begin{array}{l}\text { Overall } \\
\text { p value }\end{array}$ \\
\hline Male $(n, \%)$ & $16(35.6)$ & $12(44.4)$ & $3(17.6)$ & 0.190 \\
\hline Hypertension (n,\%) & $28(62.2)$ & $22(81.5)$ & $8(47.1)$ & 0.055 \\
\hline Diabetes mellitus $(n, \%)$ & $9(20.0)$ & $6(22.2)$ & $2(11.8)$ & 0.675 \\
\hline Smoking $(n, \%)$ & $6(13.3)$ & $4(14.8)$ & $2(11.8)$ & 0.958 \\
\hline Age (years) & $51 \pm 8$ & $65 \pm 9$ & $57 \pm 11$ & $<0.001$ \\
\hline Family history $(\mathrm{n}, \%)$ & $4(8.9)$ & $4(14.8)$ & $2(11.8)$ & 0.415 \\
\hline BUN (mg/dl) & $14 \pm 5$ & $19 \pm 10$ & $17 \pm 6$ & 0.009 \\
\hline Creatinin (mg/dl) & $0.8 \pm 0.3$ & $0.9 \pm 0.3$ & $0.8 \pm 0.2$ & 0.076 \\
\hline Fasting blood glucose (mg/dl) & $106 \pm 34$ & $121 \pm 57$ & $107 \pm 44$ & 0.236 \\
\hline Total cholesterol (mg/dl) & $208 \pm 47$ & $175 \pm 35$ & $185 \pm 36$ & 0.009 \\
\hline LDL (mg/dl) & $126 \pm 40$ & $106 \pm 30$ & $116 \pm 28$ & 0.036 \\
\hline HDL (mg/dl) & $46 \pm 11$ & $41 \pm 10$ & $43 \pm 15$ & 0.171 \\
\hline Triglyceride (mg/dl) & $174 \pm 96$ & $136 \pm 57$ & $138 \pm 66$ & 0.191 \\
\hline LVEF (\%) & $61 \pm 9$ & $52 \pm 9$ & $53 \pm 11$ & 0.002 \\
\hline VCAM -1 (mg/dl) & $1072 \pm 229$ & $1113 \pm 198$ & $1260 \pm 291$ & 0.021 \\
\hline ICAM-1 (mg/dl) & $671 \pm 132$ & $680 \pm 163$ & $748 \pm 203$ & 0.216 \\
\hline CRP (mg/dl) & $4.8 \pm 2.9$ & $5.9 \pm 5.1$ & $10.5 \pm 11.0$ & 0.163 \\
\hline
\end{tabular}

Table 1: Continuous variables are shown as mean \pm standard deviation quantitative variables are shown as numbers and percantages. NVAF: nonvalvular atrial fibrillation, VAF: valvular atrial fibrillation, BUN: blood urea nitrogen, LDL: Low-density lipoprotein, HDL: High-density lipoprotein, LVEF: left ventricular ejection fraction, VCAM: vascular cell adhesion molecule, ICAM: intercellular adhesion molecule.

\begin{tabular}{|c|c|c|c|}
\hline & Control $(\mathbf{n = 4 5})$ & VAF $(\mathbf{n = 1 7})$ & P value \\
\hline Age (years) & $51 \pm 8$ & $57 \pm 11$ & 0.104 \\
\hline BUN (mg/dl) & $14 \pm 5$ & $17 \pm 6$ & 0.253 \\
\hline Total cholesterol (mg/dl) & $208 \pm 47$ & $185 \pm 36$ & 0.130 \\
\hline LDL (mg/dl) & $126 \pm 40$ & $116 \pm 28$ & 0.564 \\
\hline VCAM -1(mg/dl) & $1072 \pm 229$ & $1260 \pm 291$ & $\mathbf{0 . 0 1 6}$ \\
\hline ICAM-1 (mg/dl) & $671 \pm 132$ & $748 \pm 203$ & 0.199 \\
\hline
\end{tabular}

Table 2: VAF: valvular atrial fibrillation, BUN: blood urea nitrogen, LDL: Lowdensity lipoprotein, VCAM: vascular cell adhesion molecule, ICAM: intercellular adhesion molecule.
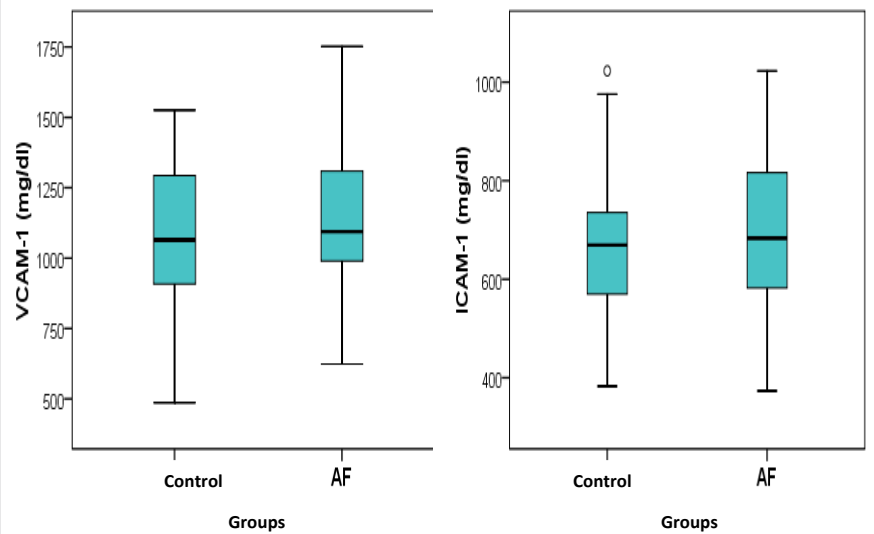

Figure 1: Distribution of VCAM-1 levels $(1072 \pm 229 \mathrm{mg} / \mathrm{dl}$ vs $1169 \pm 246$ $\mathrm{mg} / \mathrm{dl}, \mathrm{p}=0.056)$ and ICAM-1 levels at both groups $(671 \pm 132 \mathrm{mg} / \mathrm{dl} \mathrm{vs} 706$ $\pm 180 \mathrm{mg} / \mathrm{dl}, \mathrm{p}=0.313)$. AF: Atrial fibrillation, ICAM: intercellular adhesion molecule, VCAM: vascular cell adhesion molecule. 

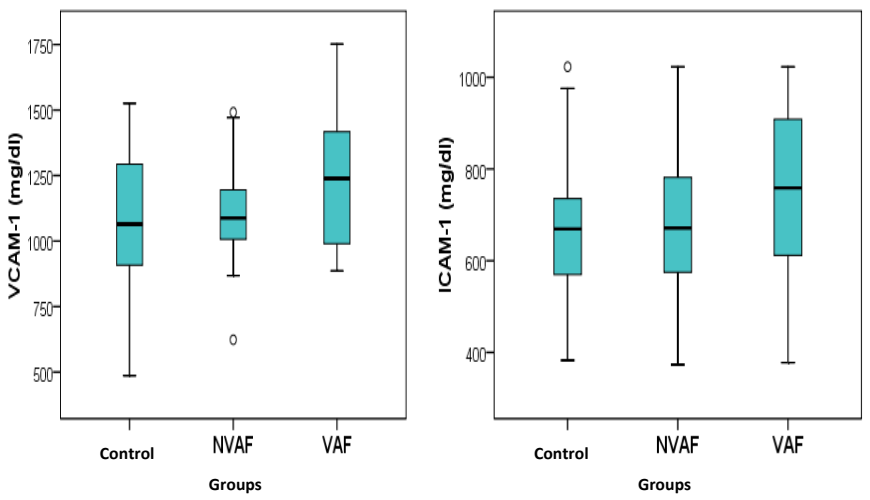

Figure 2: Distribution of VCAM-1 levels $(1260 \pm 291$ vs $1113 \pm 198$ vs $1072 \pm$ $229, p=0.021)$ and ICAM- 1 levels at study groups $(671 \pm 132$ vs $680 \pm 163$ vs $748 \pm 203, p=0.216)$. NVAF: non-valvular atrial fibrillation, VAF: valvular atrial fibrillation, VCAM: vascular cell adhesion molecule.

between the groups. Vcam-1 level was higher in the atrial fibrillation group when compared with the control group $(1169 \pm 246 \mathrm{mg} / \mathrm{dl}, 1072$ $\pm 229 \mathrm{mg} / \mathrm{dl}, \mathrm{p}=0.056$ ) (Figure 1).

In the atrial fibrillation group, there were 17 (39\%) vaf and 27 (61\%) nvaf patients. In the valvular atrial fibrillation group, there was history of valvular surgery at $8(47 \%)$ patients of which 6 for mitral valvulus and 2 for mitral valve replacement (mvr)+aortic valve replacement (avr). A statistically significant difference was detected between the valvular af, non-valvular af and control groups in terms of age and left ventricular ef values. Any difference between the valvular af, nonvalvular af and control groups in terms of icam-1 value $(748 \pm 203 \mathrm{mg} /$ $\mathrm{dl}$ vs $680 \pm 163 \mathrm{mg} / \mathrm{dl}$ vs $671 \pm 132$, $\mathrm{p}=0.216$ ), however, there was a statistically significant difference between the groups in term of vcam1 levels $(1260 \pm 291 \mathrm{mg} / \mathrm{dl}$ vs $1113 \pm 198 \mathrm{mg} / \mathrm{dl}$ vs $1072 \pm 229 \mathrm{mg} / \mathrm{dl}$, $\mathrm{p}=0.021$ ) (Figure 2). Vcam-1 level, which is higher $(1260 \pm 291 \mathrm{mg} / \mathrm{dl}$ vs. $1072 \pm 229 \mathrm{mg} / \mathrm{dl}, \mathrm{p}=0.016)$ in the vaf group than the control group is found to be the primary reason for the difference mentioned between the af and control groups in the analyses conducted. In multivariate cox regression analysis, high vcam-1 levels and high age correlation was significant $(\mathrm{p}=0.01)$ (Table 3$)$.

\section{Discussion}

In this study, we aimed to compare the icam-1 and vcam-1 levels at vaf and nvaf patients with healthy control group. Vcam-1 levels were found to be statistically significantly higher especially in patients with vaf according to the nvaf patients and control group.

Af causes significant increase in morbidity, mortality and health costs due to hemodynamic disorders, stroke and other thromboembolic complications. Overall in af, decrease in blood flow, increase in the activation of coagulation system and endothelial changes play a role in the development of thrombus. Adhesion molecules help cells to adhere both to each other and to the extracellular matrix. Some adhesion molecules that increase in the blood flow can contribute to development of intravascular thrombus by increasing the collection of cells and adhesion [11].

Pathophysiological importance of adhesion molecules in atrial fibrillation was supported by the study conducted by kamiyama. In this trial; after administering 8 hours of rapid atrial pace in the left atrium of rabbit at the endocardium increase in adhesion molecules with leucocyte adhesion was shown [17]. These data support the claim that adhesion molecules can trigger development of thrombus by achieving the adhesion of trombocytes, lecocytes and monocyte to the surface of endocardium [18]. Goette et al. Showed that vcam-1 expression increases both in paroxysmal and in persistant af [10]. Hammwöhner et al. suggested that the levels of plasma vcam-1 and icam-1 levels increase in patients with af and vcam-1 level is an independent risk factor atrial thrombus [21]. On the other hand, chen et al. Reported that there aren't any differences between the patients with lone af and control group in terms of vcam-1 and icam-1 levels [22]. Canbaz et al. in a study in which they evaluated the postoperative af development, didn't detect any relationship between the af development and vcam-1 levels [23]. Compliant with these data, in our study vcam-1 levels of patients with nvaf weren't different from those of the control subjects.

Levels of vcam-1, icam-1 and von willebrand factor were reported to be significantly higher in the patients with rheumatic heart disease (rhd) when compared with the patients without rhd [20]. Particularly in rhd cases with af, a significant increase at icam-1 levels was observed when compared with the rhd patients with normal sinus rhythm [20]. In a study conducted by yetkin et al. plasma vcam-1, icam-1 and e-selectin levels were shown to increase significantly in patients with rheumatic mitral stenosis when compared with the control group [24]. Müller et al. showed that vcam expression increases not only in inflamed cuspis but alsoin degenerative cuspis in which there is not any finding of inflammation [25]. Similarly, shahi et al. found in a study that vcam-1, icam-1 and e-selectin levels are increased in nonrheumatic aort stenosis and they suggested that non-rheumatic aort stenosis can have an inflammatory or immunological etiology [26]. Zhang et al. showed that plasma vcam-1 and icam-1 levels are higher in the patients with rheumatic heart disease when compared with the control group and for the reason of this issue they suggested that this can be one of the pathological mechanisms of myocardial damage, endothelial dysfunction and cuspis damage in patients with rheumatic heart disease [20].

In our study, we could not find any difference between the groups in terms of icam-1 level. However, we observed that vcam-1 levels are significantly higher in the vaf patients when compared with the control group subjects that don't have rhd with sinus rhythm. Although there was not any atrial thrombus in the patient group of this study, high vcam-1 levels can be related with increased risk of atrial thrombus and stroke.

Prothrombotic endothelial changes (endocardial remodeling) develop at the fibrillated atriums. Cai et al. in animal studies, reported that, during af expression of no, synthetase decreases leading to decrease in no production contributing to the thrombus development by affecting the release of adhesion molecules [27]. There are studies that suggest that, during af oxidative, stress via nADPH oxidase increases and stimulates the production of adhesion molecules [28,29]. Vcam1 levels which are one of the adhesion molecules that were evaluated in this study were found to be high. Multivariate regression analysis showed that high age and high vcam-1 level correlation is significant. Af is an age related disorder so that this result is not a surprise.

\begin{tabular}{|c|c|c|c|}
\hline & Hazard Ratio & $\mathbf{\% 9 5} \mathbf{~ C l}$ & P value \\
\hline Hypertension & 0.59 & $0.23-1.50$ & 0.27 \\
\hline Diabetes mellitus & 0.64 & $0.21-1.88$ & 0.42 \\
\hline Smoking & 1.22 & $0.23-5.33$ & 0.79 \\
\hline Age & 1.07 & $1.01-1.12$ & 0.01 \\
\hline AF & 0.88 & $0.29-2.62$ & 0.82 \\
\hline
\end{tabular}

Table 3: Multivariate cox regresyon analysis, VCAM-1 cut off value $>1200 \mathrm{mg} / \mathrm{dl}$. 
Citation: Kilci H, Koksal C, Lutfu B, Ilksen AG, Orhan O (2015) Evaluation of Increase in the Adhesion Molecules (Icam-1, Vcam-1) according to the Types of Atrial Fibrillation. J Vasc Med Surg 3: 234. doi:10.4172/2329-6925.1000234

\section{Limitations of the Study}

One of the most important limitations of this study is the lack of prospective follow-up for the thromboembolic complications of af. Another limitation is, no doubt, the low number of patients included in the study. Larger studies with a number of patients will be able to better explain the role of these molecules in atrial fibrillation. Levels of adhesion molecules are affected by multiple factors such as smoking, hypertension, age, hyperlipidemia, low level of hdl and medications [30-34]. Thus, it is very difficult to achieve a full homogenization in scope of these factors. Also, in our study the potential effects of these factors on the adhesion molecules cannot be ruled out.

\section{Conclusion}

While icam-1 levels are alike in patients with valvular atrial fibrillation and patients with sinus rhythm, vcam-1 levels are higher at patients with valvular atrial fibrillation. We suggest that high vcam-1 levels can be a risk for the development of thromboembolic events in this group.

\section{References}

1. Mcnamara RL, Brass LM, Drozda JP (2004) Acc/aha key data elements and definitions for measuring the clinical management and outcomes of patients with atrial fibrillation: a report of the american college of cardiology/american heart association task force on clinical data standards (writing commitee to develop data standards on atrial fibrillation). $\mathrm{J}$ am coll cardiol 44: 475-495.

2. Fuster V, Ryden LE, cannom DS (2006) Acc/aha/esc 2006 guidelines for the management of patients with atrial fibrillation-executive summary: a report of the american college of cardiology/american heart association task force on practice guidelines and the european society of cardiology committee for practice guidelines (writing committee to revise the 2001 guidelines for the management of patients with atrial fibrillation). $\mathrm{J}$ am coll cardiol 48: 854-906.

3. Blackshear JL, Safford RE; AFFIRM trial; RACE trial (2003) AFFIRM and RACE trials: implications for the management of atrial fibrillation. Card Electrophysiol Rev 7: 366-369.

4. Wyse DG, Waldo AL, DiMarco JP, Domanski MJ, Rosenberg Y, et al. (2002) A comparison of rate control and rhythm control in patients with atrial fibrillation. N Engl J Med 347: 1825-1833.

5. Wolf PA, Dawber TR, Thomas HE Jr, Kannel WB (1978) Epidemiologic assessment of chronic atrial fibrillation and risk of stroke: the Framingham study. Neurology 28: 973-977.

6. Aalbers $J$ (2010) Anti-thrombotic trials in atrial fibrillation, the RELY study. Cardiovasc J Afr 21: 299.

7. Ozdemir M, Türkoglu S, Kaya MG, Cengel A (2006) Prospective randomized trial of transthoracic versus low-energy internal cardioversion in persistent atrial fibrillation: long term follow-up. Int Heart J 47: 753-762.

8. Yalçin R, Kaya MG, Ozdemir M, Cemri M, Timurkaynak T, et al. (2004) Prospective randomized trial of transthoracic versus low-energy transvenous internal cardioversion in persistent atrial fibrillation. Acta Cardiol 59: 521-526.

9. Friedman PA (2007) Atrial fibrillation: pathogenesis, diagnosis and evaluation In: murphy jg, ed. Mayo clinic cardiology. (3rd edition), Rochester: mayo clinic 351-361.

10. Goette A, Bukowska A, Lendeckel U, Erxleben M, Hammwöhner M, et al (2008) Angiotensin II receptor blockade reduces tachycardia-induced atrial adhesion molecule expression. Circulation 117: 732-742.

11. Goette A, Lendeckel U, Klein HU (2002) Signal transduction systems and atrial fibrillation. Cardiovasc Res 54: 247-258.

12. Ciccone MM, Cortese F, Gesualdo M, Riccardi R, DiNunzio D, et al. (2013) A novel cardiac bio-marker: ST2: a review. Molecules 18: 15314-15328.

13. Guc D (2004) Adezyon molekülleri. Ankem derg 18: 158-163.

14. Patarroyo $M(1991)$ Leukocyte adhesion in host defense and tissue injury. Clin Immunol Immunopathol 60: 333-348.

15. Ozaki H, Ishii K, Horiuchi H, Arai H, Kawamoto T, et al. (1999) Cutting edge: combined treatment of TNF-alpha and IFN-gamma causes redistribution of junctional adhesion molecule in human endothelial cells. J Immunol 163: 553557.

16. Hammwöhner M, D'Alessandro A, Wolfram O, Goette A (2007) New pharmacologic approaches to prevent thromboembolism in patients with atrial fibrillation. Curr Vasc Pharmacol 5: 211-219.

17. Kamiyama N (1998) Expression of cell adhesion molecules and the appearance of adherent leukocytes on the left atrial endothelium with atrial fibrillation: rabbit experimental model. Jpn Circ J 62: 837-843.

18. Goette A, D’Alessandro A, Bukowska A, Kropf S, Mewis C, et al. (2008) Rationale for and design of the CREATIVE-AF trial: randomized, double-blind placebo-controlled, crossover study of the effect of irbesartan on oxidative stress and adhesion molecules in patients with persistent atrial fibrillation. Clin Drug Investig 28: 565-572.

19. Postadzhiyan AS, Tzontcheva AV, Kehayov I, Finkov B (2008) Circulating soluble adhesion molecules ICAM-1 and VCAM-1 and their association with clinical outcome, troponin $\mathrm{T}$ and $\mathrm{C}$-reactive protein in patients with acute coronary syndromes. Clin Biochem 41: 126-133.

20. Zhang QC, Yin HH, Yin BL (2005) Concentration and significance of s-ICAMs-VCAM-, and VWF in the plasma of patients with rheumatic heart disease. Zhong Nan Da Xue Xue Bao Yi Xue Ban 30: 407-409.

21. Hammwöhner M, Ittenson A, Dierkes J, Bukowska A, Klein HU, et al. (2007) Platelet expression of CD40/CD40 ligand and its relation to inflammatory markers and adhesion molecules in patients with atrial fibrillation. Exp Biol Med (Maywood) 232: 581-589.

22. Chen MC, Chang HW, Juang SS, Yip HK, Wu CJ, et al. (2004) Percutaneous transluminal mitral valvuloplasty reduces circulating vascular cell adhesion molecule-1 in rheumatic mitral stenosis. Chest 125: 1213-1217.

23. Canbaz S, Erbas H, Huseyin S, Duran E (2008) The role of inflammation in atrial fibrillation following open heart surgery. J Int Med Res 36: 1070-1076.

24. Yetkin E, Erbay AR, lleri M, Turhan H, Balci M, et al. (2001) Levels of circulating adhesion molecules in rheumatic mitral stenosis. Am J Cardiol 88: 1209-1211.

25. Müller AM, Cronen C, Kupferwasser LI, Oelert H, Müller KM, et al. (2000) Expression of endothelial cell adhesion molecules on heart valves: upregulation in degeneration as well as acute endocarditis. J Pathol 191: 54-60.

26. Shahi CN, Ghaisas NK, Goggins M, Foley B, Crean P, et al. (1997) Elevated levels of circulating soluble adhesion molecules in patients with nonrheumatic aortic stenosis. Am J Cardiol 79: 980-982.

27. Cai H, li Z, goette A (2002) Downregulation of endocardial nitric oxide synthase expression and nitric oxide production in atrial fibrillation: potential mechanisms for atrial thrombosis and stroke. Circulation 106: 2854-2858.

28. Bukowska A, Schild L, Keilhoff G, Hirte D, Neumann M, et al. (2008) Mitochondrial dysfunction and redox signaling in atrial tachyarrhythmia. Exp Biol Med (Maywood) 233: 558-574.

29. Dudley SC Jr, Hoch NE, McCann LA, Honeycutt C, Diamandopoulos L, et al. (2005) Atrial fibrillation increases production of superoxide by the left atrium and left atrial appendage: role of the NADPH and xanthine oxidases. Circulation 112: 1266-1273

30. Mazzone A, Cusa C, Mazzucchelli I, Vezzoli M, Ottini E, et al. (2001) Cigarette smoking and hypertension influence nitric oxide release and plasma levels of adhesion molecules. Clin Chem Lab Med 39: 822-826.

31. Parissis JT, venetsanou KF, Mentzikof DG (2001) Plasma levels of soluble cellular adhesion molecules in patients with arterial hypertension. Correlations with plasma endothelin-1. Eur j intern med 12: 350-356.

32. Calabresi L, Gomaraschi M, Villa B, Omoboni L, Dmitrieff C, et al. (2002) Elevated soluble cellular adhesion molecules in subjects with low HDLcholesterol. Arterioscler Thromb Vasc Biol 22: 656-661.

33. Lupattelli G, Lombardini R, Schillaci G, Ciuffetti G, Marchesi S, et al. (2000) Flow-mediated vasoactivity and circulating adhesion molecules in hypertriglyceridemia: association with small, dense LDL cholesterol particles. Am Heart J 140: 521-526.

34. Romano M, Mezzetti A, Marulli C, Ciabattoni G, Febo F, et al. (2000) Fluvastatin reduces soluble $P$-selectin and ICAM-1 levels in hypercholesterolemic patients: role of nitric oxide. J Investig Med 48: 183-189. 